\title{
Examination of P300 in Veteran Males: Aging, Physical Activity and Cognitive Processing
}

\author{
Necip Kutlu ${ }^{1}$, Gurbuz Buyukyazi ${ }^{2}$, Gulten Kaptan ${ }^{3}$, Deniz Selcuki ${ }^{4}$, Rengin Artug ${ }^{4}$
}

\begin{abstract}
Aim: In the recent years, the effects of long term exercise on physiological systems have been thoroughly investigated. The aim of this study was to investigate the effect of long-term physical exercise on cognitive processing in elderly male athletes.

Materials and Methods: Master athletes who had been exercising regularly (EME), healthy sedentary elderly volunteers (HSE) and healthy sedentary middle-aged volunteers (HSMA) were included in the study. Indirect maximum oxygen uptake capacity (VO2max) was determined by Astrand Test. Cognitive function (P300) was recorded at the same time of the day and in the same setting in all subjects

Results: Mean latency of P300 was $320.50 \pm 20.4 \mathrm{~ms}$ in EME, $344.70 \pm 24.48 \mathrm{~ms}$ in the HSE and $303.20 \pm 33.79 \mathrm{~ms}$ in the HSMA group. Mean amplitudes of P300 were $11.03 \pm 7.60 \mathrm{mV}, 10.39 \pm 5.48 \mathrm{mV}$ and $23.90 \pm 9.56 \mathrm{mV}$ in the EME, HSE and HSMA groups, respectively. Mean indirect maximum oxygen uptake capacity was $32.18 \pm 5.7,18.07 \pm 5.0$ and $15.8 \pm 5.0 \mathrm{ml} / \mathrm{min} / \mathrm{kg}$ in the HSE, EME and HSMA groups, respectively

Conclusion: Results of this study indicate that long-term regular exercise affected cognitive functions positively. Even though the difference in P300 latency and amplitude between EME and HSMA groups was not statistically significant, that between HSE and HSMA was. We conclude that long-term exercise slows down the age-related decline in physical and cognitive performance
\end{abstract}

Keywords: P300, Aerobic exercise, Aging, Male

\section{Intruduction}

Several studies have suggested that longterm exercise may have facilitating effects on general cognitive functions. Physical training

has been proposed to attenuate age-related decline in cognitive performance [1-5]. Numerous studies investigating age-related changes in performance on some cognitive tasks showed that subjects who engaged in high, as opposed to low-physical exercise performed better $[5,6,7]$, although significant differences were not always observed [8]. Exercisers at all ages are superior to sedentary individuals on tests of various types of cognitive functions, especially those cognitive functions that require faster information processing. Although, findings on the effects of aerobic fitness on mental functioning are widely more contradictory for young than for old people, a positive influence of aerobic fitness also has been reported in young men [9, 10]. Similar to physical training, acute exercise is assumed to have facilitating effects on mental functioning, but previous studies are not conclusive because of the lack of consistency in the method of testing chosen. Effects of acute exercise on cognitive performance are classically explained by the activation of

Received: 16 Jun 2014, Revised 24 Jun 2014, Accepted 24 Jun 2014, Available Online 30 Jun 2014

1Celal Bayar University, Medical School, Department of Physiology, Manisa, Turkey

2Celal Bayar University, School of Physical Education, Department of Sport, Manisa, Turkey

3 Arel University, School of Nursing, Department of Medical Nursing, Istanbul, Turkey

4Celal Bayar University, Faculty of Medicine, Department of Neurology, Manisa, Turkey

*Corresponding Author: Necip Kutlu, nkutlu@cbu.edu.tr 
the central nervous system via exerciseinduced physical arousal leading to narrowing of attentional focus [11]. However, relations between exercise and arousal are yet to be clarified [12]. Moreover, the terminology of arousal and related states, as well as the unidimensionality of the relationship between arousal and performance is disputed [13]. To better understand the effects of chronic exercise on brain functioning, electrophysiological studies have been performed. P300 and mental reaction time are considered as valuable tools for the measurement of cognitive function because they are thought to reflect neural activity underlying basic aspects of cognition. The use of P300 as a clinical evaluation tool should be revisited with contemporary theory, methods, and analysis procedures because a reliable neuroelectric measure of mental function would redefine the assessment of cognitive disorders [14, 15]. P300 latency is sensitive to neural changes in development and aging. Meta-analysis of P300 in normative aging studies by Polich suggested that P300 latency can provide useful information about cognitive aging, and that relative proportions of male and female subjects across samples could readily affect P300 latency aging correlations. During childhood and adolescence, P300 latency is inversely related to age, perhaps reflecting processes such as myelination and cognitive development [16].

Numerous studies have investigated the effects of aerobic fitness and exercise on electroencephalographic activity, which can be considered an index of cortical arousal. There is evidence that physical training may modify electrophysiological data [9, 17]. Similarly, Polich and Kok demonstrated a positive effect of physical training on P300 [16]. Dustman reported that fit elderly men showed shorter P300 latencies compared to unfit elderly men [9]. Polich and Lardon found that P300 amplitude was higher in individuals who performed high amount of exercise [18]
The P300 component and mental reaction times are considered to reflect basic cognitive processes [14]. There is evidence that aerobic physical activities which improve cardiorespiratory fitness are beneficial for cognitive function in healthy older adults, with effects observed for motor function, cognitive speed, auditory and visual attention [19]. Physical activity appears to attenuate the decline of cognitive functions typically observed in older men. The P300 component of the event-related potential (ERP) is particularly affected by aging and allows for basic neurobiological assessment of cognitive functions [20].

The aim of this study was to investigate the effect of long-term physical exercise on cognitive processing P300 event- related potential in elderly male athletes.

\begin{tabular}{|c|c|c|c|c|}
\hline Groups & $\begin{array}{c}\text { Age } \\
\text { (year) }\end{array}$ & $\begin{array}{l}\text { Height } \\
\text { (cm) }\end{array}$ & $\begin{array}{c}\text { Weight } \\
\text { (kg) }\end{array}$ & $\begin{array}{c}\mathrm{VO}_{2 \mathrm{Max}} \\
(\mathrm{min} / \mathrm{l} / \mathrm{kg})\end{array}$ \\
\hline HSMA & $35 \pm 12$ & $168 \pm 5$ & $68 \pm 5$ & $15.08 \pm 5$ \\
\hline EME & $67 \pm 6$ & $167 \pm 8$ & $71 \pm 4$ & $18.07 \pm 5$ \\
\hline HSE & $65 \pm 5$ & $169 \pm 5$ & $81 \pm 11 *$ & $32.18 \pm 5.7 *$ \\
\hline
\end{tabular}

\section{Material and Methods}

A total of 30 subjects were included in the study and they were allocated into one of three groups: Elderly veteran athletes who exercised regularly (Group EME, $\mathrm{n}=10$ ), elderly veteran athletes who led a sedentary life (Group HSE, $\mathrm{n}=10$ ) and middle aged subjects who lived sedentarily (Group HSMA, n=10). P300 was recorded at the same time of the day and in the same setting. Neurological, physical and mental examinations were carried out in each subject. All subjects were reviewed for history of migraine, psychological disorder, diabetes, hypertension, epilepsy, cancer and alcohol and smoking habits. Amplitude (size) and latency (timing) of P300 event-related potential (ERP) were measured. The study was approved by the Ethics Committee of the Celal Bayar 
University Hospital, and all subjects provided written informed consents.

Table 2: P300 amplitudes and latencies of the groups (mean $\pm \mathrm{SD}) . * \mathrm{p}<0.05$, 2-tailed value-student $\mathrm{t}$ test.

\begin{tabular}{lcc}
\hline Groups & $\begin{array}{c}\text { P300 } \\
\text { Amplitude(mV) }\end{array}$ & $\begin{array}{c}\text { P300 } \\
\text { Latency(ms) }\end{array}$ \\
\hline HSMA & $23.9 \pm 9.6$ & $303.2 \pm 33.8$ \\
$\mathbf{( n = 1 0 )}$ & $11.0 \pm 7.6$ & $320.5 \pm 20.4$ \\
ME (n=10) & $10.4 \pm 5.5^{*}$ & $344.7 \pm 24.5^{*}$ \\
\hline SE (n=10)
\end{tabular}

Electrodes were arranged in five columns, each with seven antero-posterior sites (Fig.1). Amplitude $(\mu \mathrm{V})$ is defined as the voltage difference between a pre-stimulus as the time from stimulus onset to the point of maximum positive amplitude within the latency window. In addition, P300 scalp distribution is defined as the change in component amplitude across the midline recording sites $(\mathrm{Fz}, \mathrm{Cz}, \mathrm{Pz})$, which typically increases in magnitude from the frontal to parietal electrodes. Scalp distribution effects are of considerable importance, since variation in amplitude from the manipulation of task or subject variables has been used to infer information about P300 neural generators. This task has been used to study a wide variety of information processing issues
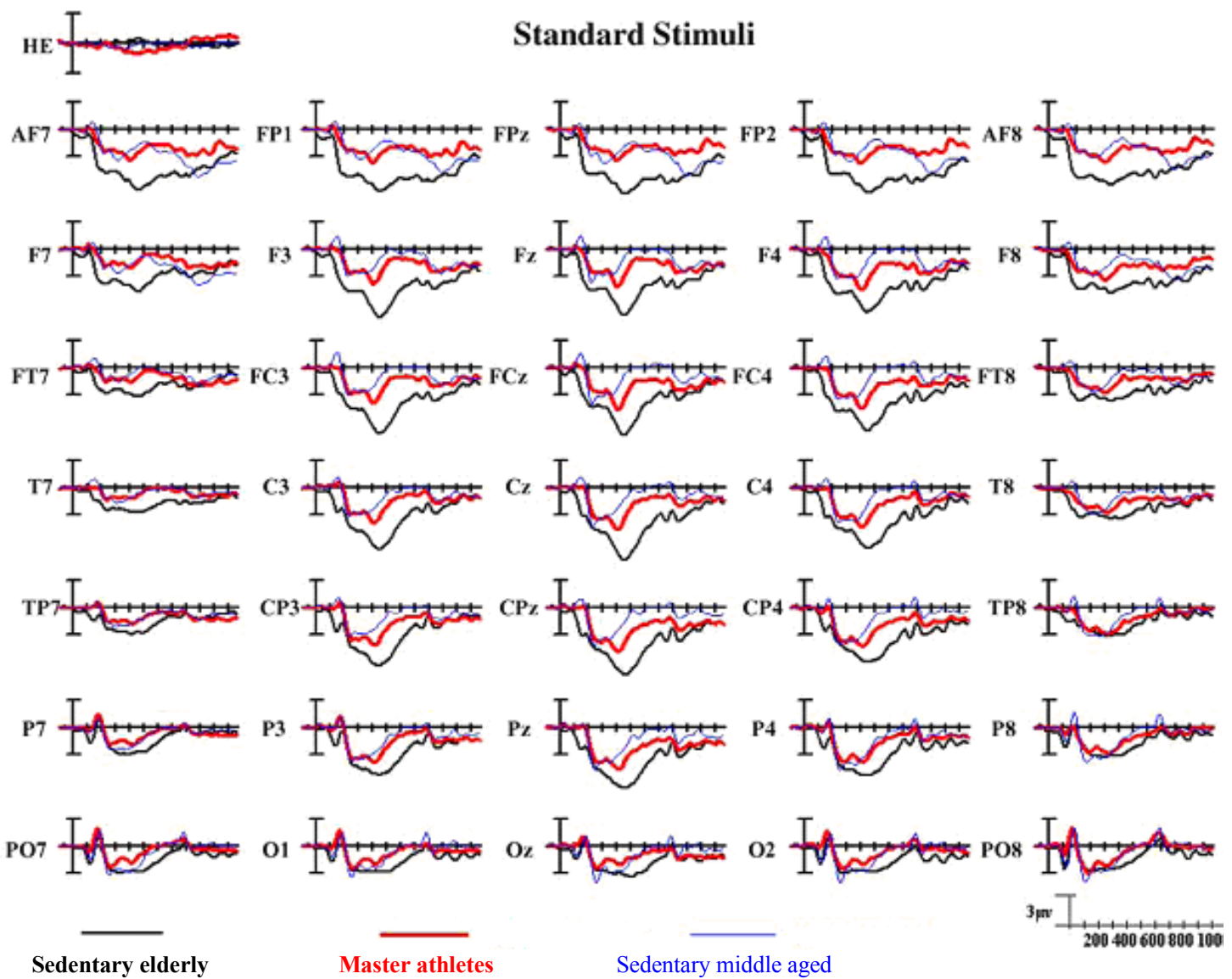

Figure 1: Standard P300 plots in healthy sedentary elderly subjects, exercising elderly master athletes and healthy sedentary middle aged subjects. Electrodes were placed according to the international 10-20 system for electrode placement, with mid-line, 2 inner-lateral and 2 outer-lateral columns [21).

baseline and the largest positive-going peak of the ERP waveform within a latency window (e.g., 250-400 ms, although the range can vary depending on stimulus modality, subject age, task conditions, etc.). Latency (ms) is defined
$[21,22]$. A strand test is given to these groups but before the test, groups were instructed not to exercise heavily. The VO2max measurement was conducted on a calibrated bicycle ergometer (Morark 860, 
Varberg, Sweden) using Astrand protocol [23].

\section{Statistical methods}

Kruskall Wallis and Mann-Whitney U tests were employed for the statistical analysis of the data, using SPSS v11.0 statistical software.

\section{Results}

Table 1 shows the P300 amplitudes and P300 latencies in the EME, HSE and HSMA groups. The statistical analyses revealed that the mean amplitude and latency of P300 of the HSE group were significantly different from the EME and HSMA groups.

Figure 1 illustrates standard P300 plots in EME, HSE and HSMA. Mean latency of P300 was $303.20 \pm 33.79 \mathrm{~ms}$ in the HSMA, $320.50 \pm 33.79 \mathrm{~ms}$ in the EME and $344.70 \pm 24.48 \mathrm{~ms}$ in the HSE group (see Figure 2).

There was a significant difference in mean P300 latency between the HSE and HSMA groups $(p<0.05)$, while the difference between EME and HSMA was not statistically significant $(\mathrm{p}>0.05)$.

Mean amplitude of P300 was 23.90 $\pm 9.56 \mathrm{mV}, 11.03 \pm 7.60 \mathrm{mV}$ and $10.39 \pm 5.48$ $\mathrm{mV}$ in the HSMA, EME and HSE groups, respectively (Figure 3). The difference in the amplitude of P300 between the HSE and HSMA groups was significant $(\mathrm{p}<0.05)$.

Table 2 shows the patient demographics and aerobic capacities of the subjects in three groups. Mean age, height and weight of the subjects in the HSE were $65 \pm 5$ years, $169 \pm 5 \mathrm{~cm}$, and $81 \pm 11 \mathrm{~kg}$, respectively. Mean age, height and weight of the subjects in the EME group were $67 \pm 6$ years, $167 \pm 8 \mathrm{~cm}$ and $71 \pm 4 \mathrm{~kg}$, respectively while those in the HSMA group were $35 \pm 12$ years, $168 \pm 5 \mathrm{~cm}$ and $68 \pm 5 \mathrm{~kg}$, respectively.

Mean VO2max in the EME and HSE groups were $18.8 \pm 5.0 \mathrm{ml} / \mathrm{min} / \mathrm{kg}$ and $32.18 \pm 5.7 \mathrm{ml} / \mathrm{min} / \mathrm{kg}, \quad$ respectively, whereas it was found to be $15.8 \pm 5.0$ $\mathrm{ml} / \mathrm{min} / \mathrm{kg}$ in the HSMA group. Statistical analyses indicated that the $\mathrm{VO} 2 \mathrm{max}$ in the HSE group was significantly higher than the EME and HSMA groups $(p<0.05)$ :

\section{Conclusion}

The results of the present study suggest that long-term exercise affects the P300 event-related potential, which is an indicator of cognitive functions. Even though the effects of long-term exercise on

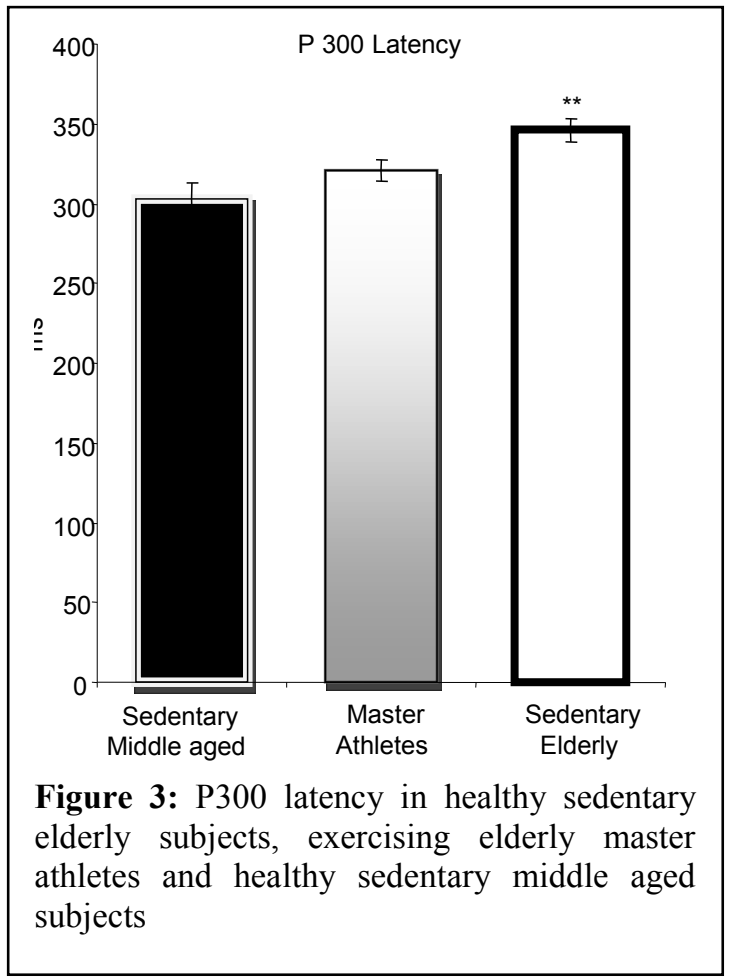

the body as a whole are well established, those on the brain need to be elucidated. We can infer information on the effects of cognitive functions by the latency and amplitude of P300 event-related potential (ERP). The theoretical interpretation of the P300 is based on: (1) neurophysiological investigations of the brain mechanisms that underlie its generation, (2) evidence from experimental studies that manipulate psychological variables, and (3) biological influences on central nervous system (CNS) function. After consideration of methodological issues, the major findings concerning P300 neural origins and psychological theory are summarized, with 
biological determinants reviewed subsequently $[24,25,26]$. Two main findings emerged in the present study. First, there were significant differences in P300 parameters between HSE and HSMA groups; whereas the differences between EME and HSMA were not. Second, there was an inverse relation between ERP amplitude and latency though the difference between the EME and HSMA groups did not reach the level of statistical significance.

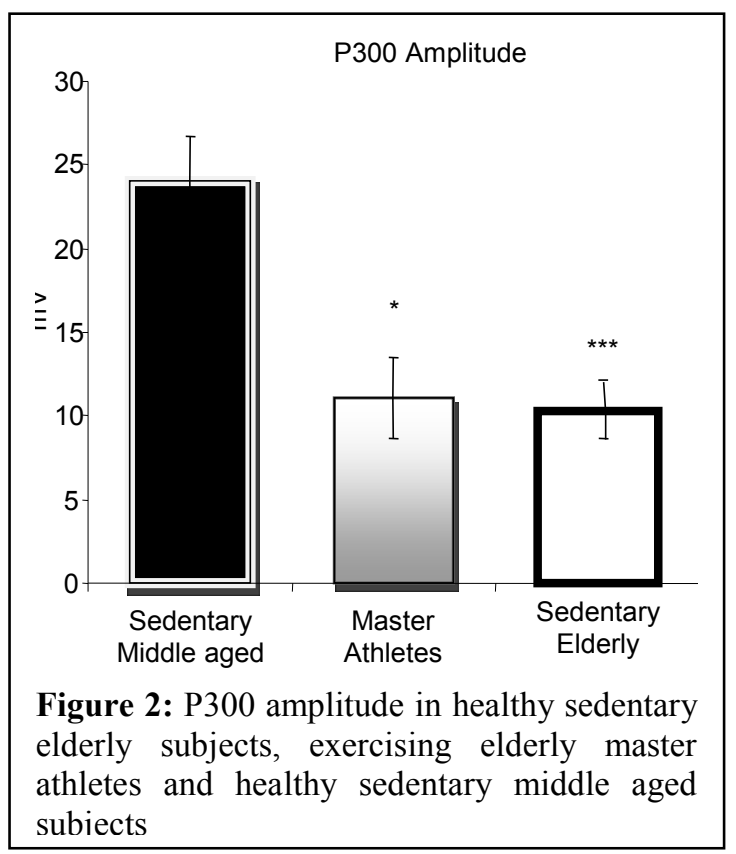

Individual fluctuations of ERP measures can occur spontaneously, or can be induced by environmental factors that exert their influence in at least two ways: a general state effect operates on the entire organism, and is assumed not to be restricted to the population of neurons influenced by a particular ERP task variables: a specific state effect means that biological conditions influence the same population of neurons as engaged by the task variables crucial for the elicitation of this particular ERP component. General and specific state factors can be organized into categories defined by the origins of the determinant: natural, induced, and constitutional. It is well known that an appreciable proportion of normal P300 variation is caused by factors related to the subject's level of arousal [27]. Many studies have been conducted to elucidate the effects of P300 biological determinants, both natural and environmental [15, 16, and 27].

Physical training can affect brain functions via several mechanisms, including promotion of cerebral blood flow, improvement in cerebral neurotransmitter function and balance, and enhancement of neuroendocrine and autonomic tone. Because some authors explained this relationship with increased circulatory capacity, it would be particularly interesting to see how the level of fitness related to an aerobic physical activity, such as cycling. It has been argued that fitnessinduced effects on ERPs might originate from fundamental changes in baseline EEG that are produced by aerobic fitness [18]. Many studies assessed EEG activity before and after exercise in a variety of subject sport-populations [9, 20, 21, and 28].

Generally similar results for P300 latency from a complex visual stimulus task in a comparable young subject group have been reported [1], although the present study also showed increased P300 amplitudes for the exercise relative to control subjects. Thus, it is reasonable to conclude that exercise does affect EEG and P300 values, but that the amount of exercise as well as the electrophysiological measurement parameters employed is important factors to consider when these variables are evaluated.

The underlying causes for the influence of physical exercise on the P300 ERP are far from clear, although speculation on the sources of these effects can be made. For example, it is straightforward to assume that physical exercise promotes cerebral blood flow (CBF) that could affect EEG measures [3, 9, 29], but why such physiologic changes would affect specific EEG bands is uncertain $[30,31]$.

However, when a decrease in CBF occurs because of anoxia or hypoxia, an increase in delta and decrease in alpha and beta activities typically are observed [32, 33].

If physical exercise promotes increased $\mathrm{CBF}$, an EEG spectral pattern opposite that of poor CBF might be obtained. Given that such EEG changes contribute to P300 
components measures, the present study is findings can be viewed as suggestive support for the hypothesis. The relationship of P300 latency to age and amplitude was tested.

The fact that $\mathrm{VO}_{2 \max }$, which shows indirect $\mathrm{O}_{2}$ consumption, while doing physical activity was higher in the HSE than EME and HSMA indicates that higher energy is spent by the subjects in HSE group while doing the same exercise $[2,3,6]$. In the present study, VO2max measurements were comparable to those reported in the literature.

Results of the present study showed that the amplitude of P300 increased with age. However, even though the difference between HSE and HSMA was significant, that between EME and HSMA was marginally significant. The difference in P300 latency between EME and HSMA was not significant despite a significant difference between HSE and HSMA. These results suggest that long-term exercise affects P300.

Even though numerous studies showed a decrease in the latency and amplitude of P300, this is one of the first studies which showed that exercise alleviated the deterioration effects of aging on brain functions. Taken together, the present results suggest that exceptional amounts of physical exercise can alter the P300 ERP component from simple auditory and visual stimuli, but that these effects are variable across subjects and most evident only with very high amounts of weekly aerobic activity [34]. Given the links between background EEG and cognitive ERPs outlined above [35,36,18], it seems likely that the effects of exercise observed for the present ERP data might originate from fundamental changes in baseline EEG that are produced by aerobic activity [17, $18,35,36,37]$.

From this point of view, extended exercise helps to contribute to increased amounts of alpha band activity and, therefore, increased P300 amplitude and decreased peak latency [36, 38]. Long-term exercise may ameliorate or protect against cognitive aging for simple stimulus discriminations [37].

Presence of statistically significant differences between the subjects in the HSMA and HSE groups as opposed to non-significant differences between the subjects in the HSMA and EME groups suggests that long-term exercise might reduce the negative effects as reflected by the less reduction of neural effort.

In conclusion, adverse effects of aging on cognitive performance may be alleviated by long time physical exercise.

\section{Conflict of Interest}

The authors declared that they had no conflicts of interest.

\section{Acknowledgements}

We would like to thanks to Dr. Siddik Keskin for statistical editing.

\section{References}

1. Bashore TR. Age, physical fitness, and mental processing speed. Annual review of gerontology \& geriatrics. 1989;9:120-44.

2. Dustman RE, Emmerson R, Shearer D. Physical activity, age and cognitive neuropsychological function. Journal of Aging Physical Activity. 1994;2:143-181.

3. Dustman RE, Emmerson RY, Ruhling RO, Shearer DE, Steinhaus LA, Johnson SC, et al. Age and fitness effects on EEG, ERPs, visual sensitivity, and cognition. Neurobiology of aging. 1990;11(3):193-200.

4. Hawkins HL, Kramer AF, Capaldi D. Aging, exercise, and attention. Psychology and aging. 1992;7(4):643-53.

5. Spirduso WW. Physical fitness, aging, and psychomotor speed: a review. Journal of gerontology. 1980;35(6):85065.

6. Dustman RE, Ruhling RO, Russell EM, Shearer DE, Bonekat HW, Shigeoka JW, et al. Aerobic exercise training and improved neuropsychological function of older individuals. Neurobiology of aging. 1984;5(1):3542 .

7. Baylor AM, Spirduso WW. Systematic aerobic exercise and components of reaction time in older women. Journal of gerontology. 1988;43(5):P121-6.

8. Blumenthal JA, Madden DJ. Effects of aerobic exercise training, age, and physical fitness on memory-search performance. Psychology and aging. 1988;3(3):280-5.

9. Dustman RE, Emmerson RY, Ruhling RO, Shearer DE, Steinhaus LA, Johnson SC, et al. Age and fitness effects on EEG, ERPs, visual sensitivity, and cognition. Neurobiology of aging. 1990;11(3):193-200. 
10. Stones MJ, Kozma A. Age, exercise, and coding performance. Psychology and aging. 1989;4(2):190-4.

11. Cote J, Salmela J, Papathanasopoulu KP. Effects of progressive exercise on attentional focus. Perceptual and motor skills. 1992;75(2):351-4.

12. Anderson KJ. Arousal and the inverted-U hypothesis: A critique of Neiss's "reconceptualizing arousal". Psychological Bulletin. 1990;107:96-100

13. Arcelin R, Delignieres D, Brisswalter J. Selective effects of physical exercise on choice reaction processes. Perceptual and motor skills. 1998;87(1):175-85.

14. Donchin E, Coles MGH. Is the P300 component a manifestation of context updating? Behavioral and Brain Sciences. 1988;11:357-374.

15. Polich J. Clinical application of the P300 event-related brain potential. Physical medicine and rehabilitation clinics of North America. 2004;15(1):133-61.

16. Polich J, Kok A. Cognitive and biological determinants of P300: an integrative review. Biological psychology. 1995;41(2):103-46

17. Lardon MT, Polich J. EEG changes from long-term physical exercise. Biological psychology. 1996;44(1):1930 .

18. Polich J, Lardon MT. P300 and long-term physical exercise. Electroencephalography and clinical neurophysiology. 1997;103(4):493-8.

19. Angevaren M, Aufdemkampe G, Verhaar HJ, Aleman A, Vanhees L. Physical activity and enhanced fitness to improve cognitive function in older people without known cognitive impairment. The Cochrane database of systematic reviews. 2008(2):CD005381.

20. McDowell K, Kerick SE, Santa Maria DL, Hatfield BD. Aging, physical activity, and cognitive processing: an examination of P300. Neurobiology of aging. 2003;24(4):597-606
21. Daffner KR, Ryan KK, Williams DM, Budson AE, Rentz $\mathrm{DM}$, Scinto LF, et al. Age-related differences in novelty and target processing among cognitively high performing adults. Neurobiology of aging. 2005;26(9):1283-95.

22. Soltani M, Knight RT. Neural origins of the P300. Critical reviews in neurobiology. 2000;14(3-4):199-224.

23. Astrand PO, Rodahl K. Training Methods and Biological Long-term. Textbook of work physiology. New York: McGraw Hill Co. 1986.

24. Bashore TR, van der Molen MW. Discovery of the P300: a tribute. Biological psychology. 1991;32(2-3):155-71.

25. Johnson R, Jr. On the neural generators of the P300 component of the event-related potential. Psychophysiology. 1993;30(1):90-7.

26. Polich J. P300 in clinical applications: Meaning, method and measurement. Niedermeyer E, Lopes da Silva F, editors. Electroencephalography: Basic principles, clinical applications, and related fields. Baltimore: Williams \& Wilkins. 1993.

27. Kok A. Internal and external control: a two-factor model of amplitude change of event-related potentials. Acta psychologica. 1990;74(2-3):203-36.

28. Boutcher SH, Landers DM. The effects of vigorous exercise on anxiety, heart rate, and alpha activity of runners and nonrunners. Psychophysiology. 1988;25(6):696-702.

29. Geisler MW, Squires NK. Exercise and pain differentially affect the P300 event-related brain potential. Psychophysiology. 1992;29:14.

30. Bashore TR, Goddard PH. Preservative and restorative effects of aerobic fitness on the age related slowing of mental speed. Cerella J, Rhybash J, Hoyer W, editors. Adult Information Processing: Limits On Loss. New York: Academic Press. 1993.

31. Dustman RE, Shearer DE, Emmerson RY. EEG and event-related potentials in normal aging. Progress in neurobiology. 1993;41(3):369-401. 